\title{
Factors effecting the outcomes of artificial urinary sphincter placement: a single-center study
}

\author{
Mustafa Murat Aydosø, Volkan Çağlayan $\odot$ \\ Department of Urology, University of Health Sciences, Bursa Yüksek İhtisas Training and Research Hospital, Bursa, Turkey
}

\section{ABSTRACT}

Objectives: To evaluate the patients who underwent artificial urinary sphincter (AUS) placement and report outcomes of the procedure.

Methods: From March 2008 to February 2017, the data of patients who have undergone AUS placement were evaluated retrospectively. Age, body-mass index (BMI), comorbidities, education level, previous radiotherapy (RT) history of the patients were recorded. Cognitive status was examined using the Mini Mental Status Examination test (MMSE). International Consultation on Incontinence Questionnaire Short Form (ICIQ-SF) was completed pre- and post-operatively. Quality of life and satisfaction of patients were evaluated using Patient Global Impression of Improvement (PGI-I) scale. To analyze factors effecting success and revision rates, patients were grouped according to age, BMI, comorbidities, smoking habbit, previous RT history and etiology of incontinence. Treatment success was defined as requirement of $\leq 1 /$ day.

Results: A total of 61 patients were included in the study and each were cognitive intact (MMSE $>25)$. ICIQSF significantly improved in postoperative period $(p<0.001)$. PGI-I median score was $1(1-4)$ in postoperative period. Success rate was $96.7 \%(n=59)$ and $47(77 \%)$ patients were complete dry. Revision requirement occured in $10(16.4 \%)$ patients. When patient groups were compared according to the success and revision rates; presence of BMI $>25 \mathrm{~kg} / \mathrm{m} 2$ was the only significant factor associated with revision requirement and there was no significant factor associated with success status.

Conclusion: AUS placement is a safe and effective method in the treatment of post-prostatectomy incontinence (PPI). Success and revision rates are similar regardless the etiology of PPI. Cognitive functions of patients may be crucial in the postoperative satisfaction status.

Keywords: Artificial urinary sphincter, post-prostatectomy incontinence, male incontinence

$S^{t}$ tress urinary incontinence (SUI) may occur in men who underwent radical prostatectomy (RP) for the treatment of localized prostate cancer (Pca).In the literature, it was reported that $8 \%$ to $25 \%$ of the men were affected by persistent UI following RP [1-4]. Besides, as a more widespread procedure performed in urology practice, transurethral resection of the prostate (TUR-P) is associated with postoperative urinary in- continence range 1.8 to $5 \%$. [5-8]. Although it is not a lethal complication, SUI following prostate surgery (RP or TUR-P)may impact the quality of life adversely and cause financial problems.Internal urethral sphincter deficiency is the main reason associated with SUI in men. Nowadays artificial urethral sphincter (AUS) placementis the standart treatment of moderate and severe postprostatectomy incontinence [9-11]. However,

Received: December 27, 2018; Accepted: February 7, 2019; Published Online: February 8, 2019

How to cite this article: Aydos MM, Çağlayan V. Factors effecting the outcomes of artificial urinary sphincter placement: a single-center study. Eur Res J 2020;6(4):276-282. DOI: 10.18621/eurj.503382

Address for correspondence: Volkan Çağlayan, MD., University of Health Sciences, Bursa Yüksek İhtisas Training and Research Hospital, Department of Urology, Mimar Sinan Mahallesi, Emniyet Cd. No:35, 16310 Yıldırım, Bursa, Turkey. E-mail: volkantuysuz@hotmail.com, Tel: +90 224 295 50 00 
success of this system can be affected by many factors such as previous radiation therapy (RT), bladder neck or urethral stenosis, comorbidities of the patient and surgeon's experience. Additionally complications such as infection, urethral erosion, urethral atrophy and device malfunction may occur following the procedure. Although it is an effective treatment, the patients may be disappointed because of high expectations from the device. Patients should be informed about the device, the possible complications and the definition of success.

AUS placement has been performed in our clinic since 2008. In this study, we aimed to evaluate the patients who underwent AUS placement and report our results.

\section{METHODS}

In this retrospective study, the data of the patients who have undergone AUS placement (AMS 800) in our clinic since 2008 were evaluated. The patients with more than one year follow-up were included. The age, body-mass index, comorbidities, education level, previous RT history and urethral or bladder neck stenosis history of the patients were recorded. Cognitive status was examined using the Mini Mental Status Examination test (MMSE). International Consultation on Incontinence Questionnaire Short Form (ICIQ-SF) was completed in all patients before and 3 months after the treatment. The quality of life and satisfaction of the patients were evaluated using Patient Global Impression of Improvement (PGI-I) scalewhich is a transition scale that is a single question asking the patient to rate their urinary tract condition now, as compared with how it was prior to the treatment on a range from 1 (very much better) to 7 (very much worse).Filling these forms was a routine procedure as it was mandatory for preoperative decision-taking and postoperative follow-up. Number of pads used before and two months after the treatment were also recorded. Postoperative complications were assessed using Clavien-Dindo grading system [12]. Treatment success was defined as the requirement of maximum one pad per day. The patients who did not need any pad use were defined as complete dry. Additionally, to analyze the factors effecting success rate and revision rate, patients were grouped according to the age ( $\geq 65$ years and $<65$ years), BMI ( $\geq 25$ $\mathrm{kg} / \mathrm{m}^{2}$ and $\left.<25 \mathrm{~kg} / \mathrm{m}^{2}\right)$, comorbidities, smoking habbit, previous RT history, education level (lower than high school - high school and above) and etiology of incontinence.

Urine culture was sterile in all cases in the operation day. Ceftriaxone $1 \mathrm{gr}$ intravenous was administered to all patients prior to the surgery in the operating room. The perineal area was shaved in the operating room and washed with povidone-iodine for 10 minutes.

\section{Surgical Technique}

A diagnostic cystoscopy was performed prior the treatment in all cases. If an urethral or bladder neck stenosis were seen, they were treated and the treatment was delayed for two months. All the procedures were performed using a modifiedperineoscrotal vertical single incision by the same surgeon. Following the placement of urethral cuff, fascia transversalis was opened and dilated with finger. Following finger dilation, reservoir balloon was forwarded through the Retzius space. The connector tubes and control pump was placed in the scrotum. A 12 F Foley cathater was inserted during the procedure and removed in the postoperative day morning. All the patients were discharged in the postoperative day 1 and 7 days of amoxicillin/clavulanic acid 875/125 mg peroral BID was administered for each. The device was left deactivated for 6 weeks.

\section{Statistical Analysis}

Descriptive statistics for normally distributed continuous variables are reported as the mean \pm standard deviation, with median (minimummaximum) values calculated for non-normal distributions. Comparisons between groups were evaluated using the Fisher exact test for categorical variables and Wilcoxon test was used for continuous variables. The data was analyzed with IBM SPSS (version 20), and $p<0.05$ was considered as significant.

\section{RESULTS}

From March 2008 to February 2017, a total of 66 patients who underwent AUS placement in our clinic 


\section{Table 1. Patient characteristics}

\begin{tabular}{lc}
\hline Age $($ years $)$ & $69.69 \pm 5.45$ \\
BMI $\left(\mathrm{kg} / \mathrm{m}^{2}\right)$ & $25.47(22.28-31.53)$ \\
\hline Diabetes Mellitus, $\mathrm{n}(\%)$ & $12(19.7)$ \\
Hypertension, n (\%) & $23(37.7)$ \\
Coronary Artery Disease, n (\%) & $13(21.3)$ \\
Smoking, n (\%) & $20(32.8)$ \\
Previous Radiotherapy, n (\%) & $7(11.5)$ \\
\hline
\end{tabular}

were included in the study. Of the patients, 5 were lost to control and excluded. Patient demographics was shown in table 1.

All the patients completed MMSE and each were cognitive intact (MMSE > 25). The comparison of preand post-operative ICIQ-SF results of the patients was demonstrated in table 2. Questinnarie results significantly improved in the post-operative period ( $p$ $<0.001)$. Also, PGI-I median score was $1(1-4)$ in the antibiotic solution and povidone-iodine then scrotum skin was closed with suturation. Infection occurred in 2 patients and urethral erosionoccurred in 1 patient in the postoperative period. The device was removed and the revision was performed 3-6 months later. Urethral atrophy occured in 4 men and they were treated with tandem-cuff placement. Additionally, revision was performed due to the dysfunction of device in 2 men.

The comparisons of the patient groups according to the success rate and the revision rate were demonstrated in table 4 . The presence of $\mathrm{BMI} \geq 25$ $\mathrm{kg} / \mathrm{m}^{2}$ was the only significant factor associated with revision requirement. There was no significant factor associated with success status.

\section{DISCUSSION}

AUS, which was first described by Scott et al. [13] in 1973, is the standart tool for the treatment of post-

\section{Table 2. The comparsion of pre- and post-operative ICIQ-SF and median value of} post-operative PGI-I

\begin{tabular}{lccc}
\hline & Preoperative & Postoperative & $\boldsymbol{p}$ value \\
\hline ICIQ-SF (median) & $20(17-21)$ & $1(0-20)$ & $<\mathbf{0 . 0 0 1}$ \\
PGI-I (median) & $1(1-4)$ & \\
\hline ICIQ-SF: International Consultation on Incontinence & Questionnaire & Short & Form ;PGI-I: Patient Global \\
Impression of Improvement & &
\end{tabular}

post-operative period (Table 2).

The success rate of the procedure was $96.7 \%(\mathrm{n}=$ $59)$ and $47(77 \%)$ patients were complete dry. Any complications did not occur peroperatively. Revision requirement occured in $10(16.4 \%)$ patients (Table 3 ). Skin extrusion of control pump and connector tubes occured in one patient. The vehicle was washed with

\section{Table 3. Revision requirements}

\begin{tabular}{ll}
\hline Urethral erosion $(\mathrm{n} / \% / \mathrm{CDc})$ & $1 / 1.6 / 3 \mathrm{~b}$ \\
Skin extrusion $(\mathrm{n} / \% / \mathrm{CDc})$ & $1 / 1.6 / 3 \mathrm{~b}$ \\
Urethral atrophy $(\mathrm{n} / \% / \mathrm{CDc})$ & $4 / 6.5 / 3 \mathrm{~b}$ \\
\hline Device dysfunction $(\mathrm{n} / \% / \mathrm{CDc})$ & $2 / 3.2 / 3 \mathrm{~b}$ \\
Infection $(\mathrm{n} / \% / \mathrm{CDc})$ & $2 / 3.2 / 3 \mathrm{~b}$ \\
\hline
\end{tabular}

$\mathrm{CDc}=$ Clavien-Dindo classification prostatectomy incontinence (PPI). Initially, neurogenicurinary incontinence was the main indication for AUS placement. In time, with the increase of RP cases by the widespread use of prostate spesific antigen (PSA), PPI became the most frequent reason and the number of procedures increased dramatically. In the literature, there are various studies assessing the efficacy of the device, demonstrating success rates range from 61 to $100 \%$ [14]. In our study, compatibly with the literature, the success rate and complete dryness rate were $96.7 \%$ and $77.4 \%$, respectively. To increase the success rate, the placement of 2 cuffs weredescribed by Kowalczyk et al. [15]. However as most urologists, we preferred tandem-cuff only for the cases who needed revision surgery because of urethral atrophy.

Previous RT is a major concern about the success 
Table 4. Comparison of the patient groups according to the success rate and revision rate

\begin{tabular}{|c|c|c|c|c|}
\hline & $\begin{array}{c}\text { Success } \\
\text { n (\%) } \\
59(96.7)\end{array}$ & p value & $\begin{array}{c}\text { Revision } \\
\text { n (\%) } \\
10(16.4)\end{array}$ & p value \\
\hline \multicolumn{5}{|c|}{ Age (year) } \\
\hline$<65$ & $14(100)$ & 0.433 & $2(14.3)$ & 0.808 \\
\hline$\geq 65$ & $45(95.7)$ & & $8(17)$ & \\
\hline \multicolumn{5}{|c|}{ BMI $\left(\mathrm{kg} / \mathrm{m}^{2}\right)$} \\
\hline$<25$ & $25(100)$ & 0.231 & $1(4)$ & 0.029 \\
\hline$\geq 25$ & $34(94.4)$ & & $9(25)$ & \\
\hline \multicolumn{5}{|l|}{ DM } \\
\hline No & $48(98)$ & 0.273 & $8(16.3)$ & 0.977 \\
\hline Yes & $11(91.7)$ & & $2(16.7)$ & \\
\hline \multicolumn{5}{|l|}{ HT } \\
\hline No & $37(97.4)$ & 0.715 & 7 (18.4) & 0.729 \\
\hline Yes & $22(95.7)$ & & $3(13)$ & \\
\hline \multicolumn{5}{|l|}{ CAD } \\
\hline No & 47 (97.7) & 0.314 & $8(16.7)$ & 0.912 \\
\hline Yes & $12(92.3)$ & & $2(15.4)$ & \\
\hline \multicolumn{5}{|c|}{ Previous RT } \\
\hline No & $52(96.3)$ & 0.605 & $10(18.5)$ & 0.748 \\
\hline Yes & $7(100)$ & & $1(14.3)$ & \\
\hline \multicolumn{5}{|c|}{ Education level } \\
\hline Low & $24(96)$ & 0.792 & $5(20)$ & 0.526 \\
\hline High & $35(97.2)$ & & $5(13.9)$ & \\
\hline \multicolumn{5}{|l|}{ Smoking } \\
\hline No & $41(100)$ & 0.104 & $2(10)$ & 0.346 \\
\hline Yes & $18(90)$ & & $8(19.5)$ & \\
\hline \multicolumn{5}{|c|}{ Etiology of PPI } \\
\hline $\mathrm{RP}$ & $43(97.7)$ & 0.483 & $9(20.5)$ & 0.168 \\
\hline TUR-P & $16(94.1)$ & & $1(5.9)$ & \\
\hline
\end{tabular}

$\mathrm{BMI}=$ Body-mass index, DM $=$ Diabetes mellitus, $\mathrm{HT}=$ Hypertension, $\mathrm{CAD}=$ Coronary artery disease, $\mathrm{RT}=$ Radiotherapy, PPI $=$ Post-prostatectomy incontinence, $\mathrm{RP}=$ Radical prostatectomy, TUR-P $=$ Transurethral resection of prostate

of device and complications. RT may decrease vascularity and increase fibrosis in bulbar urethra. Therefore it was speculated that, prior radiation therapy increases the risk of urethral atrophy and may increase the chance of cuff erosion [16]. Also in the consensus of the International Continence Society, RT was revealed as a factor which predisposes complications [17]. There are contoversial results in the literature. In the study performed by Ravier et al. [18], there was no statistically significant difference in continence status between irradiated and nonirradiated group. However, patients with prior RT were more prone to infection and explantation [18]. In another study, similar social continence rates and 
complication rates were demonstrated in two groups [19]. In our cohort, 7 patients were irradiated prior to the surgery and success rate of this group was $100 \%$. Also only one patient needed revision due to the mechanical dysfunction 5 years after the surgery. Regarding our limited data, previous RT should not be a concern for the treatment.

Infection following AUS placement is a devastating problem. As any prosthetic device, AUS is prone to infection. In the literature, infection rates range from $1 \%$ to $8 \%$ [20-23]. In the management, the device is removed and revision is performed after 3 months or more. It was revealed that a new device may be implanted with similar success rates [24]. In 2007, AMS presented InhibiZone-coated (rifampin and minocycline hydrochloride coating) AUS to reduce infection rate, however in the study performed by de Cogain et al. [20], it was revealed that antibiotic coating did not impact the infection rate and increased the cost of the device. Infection is commonly associated with urethral erosion. In our study, infection rate was $3.2 \%$ (2 patients), however in our infected patients urethral erosion did not occur. In the study performed by Bryan et al. [25], immediate replacement for the infected patients without erosion was revealed as a valid option. We preferred the classic management as we think it is safer. Of the patients, 1 was completely dry and 1 was incontinent following the revision.

The periurethral tissue should be protected during dissection to avoid the erosion after the procedure. Erosion rates in contemporary series range from 2-15 $\%[14,19,26,27]$. Erosion in the early period is commonly associated with unrecognized injury, in the late periodis with iatrogenic reasons. In our study, erosion occured in only 1 patient due to the urethral cathaterization in emergency service 2 years after the surgery. Subsequent to the unsuccessful cathaterization trial in emergecy service, suprapubic cathaterization was performed by us. Management of the urethral erosion is not clear. To remove only the cuffinstead of the whole device in the non-infected cases is the primary suggestion. We removed the whole device and performed urethroplasty. Following the revision (4 months later), continence was not achieved. This was related with the urethral atrophy due to the damaged tissue vascularization.

A disadvantage of AUS is the periodic revision requirement of the device. In the study performed by Linder et al. [10], of 1082 patients, 338 were undergone revision surgery due to the infection or erosion, device malfunction, urethral atrophy and pump malposition or tubing complications. They reported AUS survival rate of $90 \%$ at 1 year, $74 \%$ at 5 years, $57 \%$ at 10 years and $41 \%$ at 15 years [10]. Urethral atrophy is the most frequent indication of revision in long term follow-up. Itis associated with continuous pressure on the tissue and damaged vascularization of the area and causes increased incontinence. Down-sizing the cuff and increasing fluid in the system are treatment choices, however we prefer to implant a tandem cuff. In our cohort, atrophy occured in four patients and the revision procedure was successful in all cases. Additionally; as any prosthetic device, mechanical dysfunction can occur in AUS. Linder et al. [10], revealed that to replace the whole device instead of the dysfunctioning part achieved better results. In our clinical practice, we prefer to replace the whole device and continence was achieved in two patients who underwent revision surgery due to the device malfunction.

The AUS remains the most effective long-term surgical treatment for SUI in men. Despite to the high success rate, it is not suitable for some patients. To be able to use this mechanic device, a sufficient intelligence level and dexterity is an important requirement. Considering this; since AUS placement was first performed in our clinic, all the patients have completed MMSE test prior to the surgery. As far as we know, there is not any study assessing the preoperative cognitive status of the patients. In the current study, the patients completed MMSE prior to the surgery. We believe that to obey the directives and correctly use of this device may cause more satisfactory results and a longer device life. Perhaps as a result of all the patients' being cognitive intact (MMSE > 25), satisfaction rate was prominently high [PGI-I median= $1(1-4)]$ in our study.

To our knowledge, there is not a study assessing the outcomes of the AUS placement according to the etiology of PPI. In this study, we divided the patients into two groups as those who had undergone TUR-P and those who had undergone RP. Any statistically significant difference was not observed between the success and revision rates when groups were compared. However, the number of patients was low 
and further studies should be performed.

As known,the incidence of chronic diseases increases by the ageing [28]. In the literature, the number of the studies evaluating the outcomes of AUS placement in elderly males is lacking. Also controversial results were revealed. In the study performed by O'Connor et al. [29], age of the patient was not defined as a factor which adversely effects the outcomes of the procedure. However, Ziegelmann et al. [30] reported that older males were significantly more likely to experience device infection/erosion compared with younger patients. In the current study, presence of comorbidities and age $\geq 65$ years were not associated with success of the operation or revision requirements. We think that AUS placement can be safely performed in elderly patients.

\section{Limitations}

There are some limitations of this study. First,it was a retrospective non-randomized design. The data such as detailed pathology results of the patients, length of incontinence period prior to the surgery, the medications used, could not be evaluated. Second, the number of patients was relatively low. Third, it was a single center and single surgeon study, which may limit generalizability.

\section{CONCLUSION}

The AUS placement is a safe and effective method in the treatment of SUI in men regardless the patient's age. Patient counseling about the definition of success and periodic revision requirement is important prior to the surgery. The success and revision rates are similar regardless the etiology of incontinence (TURP or RP). The patients who are cognitive intact and who have sufficient dexterity may be more satisfied from the device.

\section{Conflict of interest}

The authors disclosed no conflict of interest during the preparation or publication of this manuscript.

\section{Financing}

The authors disclosed that they did not receive any grant during conduction or writing of this study.

\section{REFERENCES}

[1] Holm H, Fossa S, Hedlund H, Schultz A, Dahl AA. How should continence and incontinence after radical prostatectomy be evaluated? A prospective study of patient ratings and changes with time. J Urol 2014;192:1155-61.

[2] Stanford JL, Feng Z, Hamilton AS, Gilliland FD, Stephenson RA, Eley JW, et al. Urinary and sexual function after radical prostatectomy for clinically localized prostate cancer: the prostate cancer outcomes study. JAMA 2000;283:354-60.

[3] Potosky AL, Davis WW, Hoffman RM, Stanford JL, Stephenson RA, Penson DF, et al. Five-year outcomes after prostatectomy or radiotherapy for prostate cancer: the Prostate Cancer Outcomes Study. J Natl Cancer Inst 2004;96:1358-67.

[4] Tienza A, Robles JE, Hevia M, Algarra R, Diez-Caballero F, Pascual JI. Prevalence analysis of urinary incontinence after radical prostatectomy and influential preoperative factors in a single institution. Aging Male 2018;21:24-30.

[5] Kuntz RM, Ahyai S, Lehrich K, Fayad A. Transurethral holmium laser enucleation of the prostate versus transurethral electrocautery resection of the prostate: a randomized prospective trial in 200 patients. J Urol 2004:172:1012-6.

[6] Muzzonigro G, Milanese G, Minardi D, Yehia M, Galosi AB, Dellabella M. Safety and efficacy of transurethral resection of prostate glands up to $150 \mathrm{ml}$ : a prospective comparative study with 1 year of followup. J Urol 2004:172:611-5.

[7] Rassweiler J, Teber D, Kuntz R, Hofmann R. Complications of transurethral resection of the prostate (TURP)--incidence, management, and prevention. Eur Urol 2006:50:969-79.

[8] Reich O, Gratzke C, Bachmann A, Seitz M, Schlenker B, Hermanek P, et al. Morbidity, mortality and early outcome of transurethral resection of the prostate: a prospective multicenter evaluation of 10,654 patients. J Urol 2008:180:246-9.

[9] Montague DK. Artificial urinary sphincter: long-term results and patient satisfaction. Adv Urol 2012;2012:835290.

[10] Linder BJ, Rivera ME, Ziegelmann MJ, Elliott DS. Longterm outcomes following artificial urinary sphincter placement: an analysis of 1082 cases at Mayo Clinic. Urology 2015;86:6027.

[11] Trigo Rocha F, Gomes CM, Mitre AI, Arap S, Srougi M. A prospective study evaluating the efficacy of the artificial sphincter AMS 800 for the treatment of postradical prostatectomy urinary incontinence and the correlation between preoperative urodynamic and surgical outcomes. Urology 2008;71:85-9.

[12] Dindo D, Demartines N, Clavien PA. Classification of surgical complications: a new proposal with evaluation in a cohort of 6336 patients and results of a survey. Ann Surg 2004;240:205-13.

[13] Scott, FB., Bradley WE, Timm GW. Treatment of urinary incontinence by implantable prosthetic sphincter. J Urol 1974; 112:75-80.

[14] Van der Aa F, Drake MJ, Kasyan GR, Petrolekas A, Cornu JN. The artificial urinary sphincter after a quarter of a century: a critical systematic review of its use in male non-neurogenic incontinence. Eur Urol 2013;63:681-9.

[15] Kowalczyk JJ, Spicer DL, Mulcahy JJ. Long-term 
experience with the double-cuff AMS 800 artificial urinary sphincter. Urology 1996;47:895-7.

[16] Manunta A, Guille F, Patard JJ, Lobel B. Artificial sphincter insertion after radiotherapy: is it worthwhile? BJU Int 2000;85:490-2.

[17] Biardeau X, Aharony S, AUS Consensus Group, Campeau L, Corcos J. Artificial Urinary Sphincter: Executive Summary of the 2015 Consensus Conference. Neurourol Urodyn 2016;35(Suppl 2):S5-7.

[18] Ravier E, Fassi-Fehri H, Crouzet S, Gelet A, Abid N, Martin $\mathrm{X}$. Complications after artificial urinary sphincter implantation in patients with or without prior radiotherapy. BJU Int 2015;115:300-7.

[19] Sathianathen NJ, McGuigan SM, Moon DA. Outcomes of artificial urinary sphincter implantation in the irradiated patient. BJU Int 2014;113:636-41.

[20] de Cogain MR, Elliott DS. The impact of an antibiotic coating on the artificial urinary sphincter infection rate. J Urol 2013;190:113-7.

[21] Bordenave M, Rouprêt M, Taksin L, Parra J, Cour F, Richard $\mathrm{F}$, et al. Long-term results of the treatment of urinary incontinence with bulbar implantation of artificial urinary sphincter in men: a single-center experience. Prog Urol 2011;21:277-82.

[22] Montague DK, Angermeier KW. Postprostatectomy urinary incontinence: the case for artificial urinary sphincter implantation. Urology 2000;55:2-4.

[23] Suarez OA, McCammon KA. The artificial urinary sphincter in the management of incontinence. Urology 2016;92:14-9.

[24] Motley RC, Barrett DM. Artificial urinary sphincter cuff erosion. Experience with reimplantation in 38 patients. Urology 1990;35:215-8.

[25] Bryan DE, Mulcahy JJ, Simmons GR. Salvage procedure for infected noneroded artificial urinary sphincters. J Urol 2002;168:2464-6.

[26] Brant WO, Erickson BA, Elliott SP, Powell C, Alsikafi N, McClung $\mathrm{C}$, et al. Risk factors for erosion of artificial urinary sphincters: a multicenter prospective study. Urology 2014;84:934-8.

[27] Kim SP, Sarmast Z, Daignault S, Faerber GJ, McGuire EJ, Latini JM. Long-term durability and functional outcomes among patients with artificial urinary sphincters: a 10-year retrospective review from the University of Michigan. J Urol 2008;179:19126.

[28] Barnett K, Mercer SW, Norbury M, Watt G, Wyke S, Guthrie B. Epidemiology of multimorbidity and implications for health care, research, and medical education: a cross-sectional study. Lancet 2012;380:37-43.

[29] O'Connor RC, Nanigian DK, Patel BN, Guralnick ML, Ellision LM, Stone AR. Artificial urinary sphincter placement in elderly men. Urology 2007;69:126-8.

[30] Ziegelmann MJ, Linder BJ, Rivera ME, Viers BR, Rangel LJ, Elliott DS. Outcomes of artificial urinary sphincter placement in octogenarians. Int J Urol 2016;23:419-23. 